NBER WORKING PAPER SERIES

\title{
THE IMPACT OF A GOVERNMENT RISK POOL AND AN OPT-OUT FRAMING ON DEMAND FOR EARTHQUAKE PROTECTION
}

\author{
Howard Kunreuther \\ Lynn Conell-Price \\ Paul Kovacs \\ Katsuichiro Goda \\ Working Paper 29144 \\ http://www.nber.org/papers/w29144
NATIONAL BUREAU OF ECONOMIC RESEARCH
1050 Massachusetts Avenue
Cambridge, MA 02138
August 2021

Bohan Li and Jim Harries provided helpful comments on an earlier draft of this paper. Funding support for this research comes from the Institute for Catastrophic Loss Reduction and the Insurance Bureau of Canada. The views expressed herein are those of the authors and do not necessarily reflect the views of the National Bureau of Economic Research.

NBER working papers are circulated for discussion and comment purposes. They have not been peer-reviewed or been subject to the review by the NBER Board of Directors that accompanies official NBER publications.

(C) 2021 by Howard Kunreuther, Lynn Conell-Price, Paul Kovacs, and Katsuichiro Goda. All rights reserved. Short sections of text, not to exceed two paragraphs, may be quoted without explicit permission provided that full credit, including $\odot$ notice, is given to the source. 
The Impact of a Government Risk Pool and an Opt-Out Framing on Demand for Earthquake Protection

Howard Kunreuther, Lynn Conell-Price, Paul Kovacs, and Katsuichiro Goda

NBER Working Paper No. 29144

August 2021

JEL No. D81,G22,H12,H44

\begin{abstract}
$\underline{\text { ABSTRACT }}$
This paper describes the design and analysis of a web-based choice experiment that examines how the demand for earthquake protection in Quebec and British Columbia is influenced by the default option and the structure of the insurance plan. Homeowners in both provinces were given the opportunity to purchase protection against earthquake losses when presented with one of the following options: the current private insurance plan, a high deductible private insurance plan, and a proposed public-private risk pool. The default frame was changed so the homeowner could either opt-in by purchasing this coverage or opt-out of being given this protection and receiving a premium discount. Assigning participants to a public-private risk pool rather than the current private insurance plan increases the likelihood of purchasing earthquake protection by $151 \%$. The opt-out frame leads to a likelihood greater than 1.6 of purchasing coverage relative to the opt-in frame when given the same plan structure. The policy implications of this finding are discussed.
\end{abstract}

\author{
Howard Kunreuther \\ Wharton Risk Management \\ and Decision Processes Center \\ The Wharton School \\ University of Pennsylvania \\ 3819 Chestnut Street, Room 217 \\ Philadelphia, PA 19104-6366 \\ and NBER \\ kunreuth@wharton.upenn.edu \\ Lynn Conell-Price \\ Wharton Risk Management and \\ Decision Processes Center \\ University of Pennsylvania \\ lynncp@wharton.upenn.edu
}

\author{
Paul Kovacs \\ Institute for Catastrophic Loss Reduction \\ 20 Richmond Street East, Suite 210 \\ Toronto \\ Canada \\ pkovacs@iclr.org \\ Katsuichiro Goda \\ Department of Earth Sciences \\ Western University, Canada \\ 1151 Richmond Street N. \\ Office: BGS 1076 \\ London, Ontario, N6A 5B7 \\ Canada \\ kgoda2@uwo.ca
}




\title{
The Impact of a Government Risk Pool and an Opt-Out Framing on Demand for Earthquake Protection
}

\author{
Howard Kunreuther, Lynn Conell-Price, Paul Kovacs, and Katsu Goda
}

August 3, 2021

\section{Overview}

This report describes the design and analysis of a hypothetical choice survey experiment with homeowners in Quebec and British Columbia (BC) examining how their propensity to purchase earthquake protection on a property is influenced by the default option and the structure of the insurance plan they are asked to consider.

The report is organized as follows. Section 2 provides a brief background on the policy context and academic literature motivating the main hypotheses of interest. Section 3 describes the design of the experiment to test these hypotheses and details the study procedures. Section 4 presents the results of the study. The concluding section discusses the main takeaways from our empirical findings.

\section{Background and Hypotheses}

Many Canadians own homes exposed to an earthquake hazard and much of the risk of costly residential damages from a severe quake is concentrated in Quebec in the East and British Columbia (BC) in the West-regions where high population density and seismic activity overlap.

Historically, many different types of earthquake disasters have occurred in Canada. One way to characterize the severity of an earthquake is by measuring its magnitude (M), the amount of energy released by the earthquake. ${ }^{1}$ Major earthquakes in western Canada include the 1700 (M9) Cascadia mega-thrust subduction earthquake off Vancouver Island, the 1918 (M6.9) and 1946 (M7.3) shallow crustal earthquakes on Vancouver Island, and the 2001 (M6.8) Nisqually deep inslab earthquake centered in Washington, United States. In eastern Canada, major damaging crustal events between M6 and M7.5 occurred in the Charlevoix seismic zone (in 1663, 1860, 1870, 1925, and 1971), while moderate earthquakes occurred in the Western Quebec seismic region (in 1732, 1935, 1944, and 2010) (see Cassidy et al., 2010 for review of major events).

\footnotetext{
${ }^{1}$ The United States Geological Survey (USGS) describes earthquakes as minor (M3.0 - 3.9), high (M4.0 - 4.9), moderate (M5.0 - 5.9), strong (M6.0 - 6.9), major (M7.0 - 7.9) and great (M8.0 or higher). For more details on the severity of earthquakes see http://geology.teacherfriendlyguide.org/index.php/hazards-w/hazards-earthquakes-w
} 
A study commissioned by the Insurance Bureau of Canada and conducted by AIR Worldwide examined hypothetical earthquake scenarios for Quebec and BC to provide insight on the anticipated scale of damages should significant earthquakes occur today (Insurance Bureau of Canada \& AIR Worldwide, 2013). While the likelihood of these scenarios occurring in any given year is very low, they illustrate the extent of losses that are likely to be borne directly by homeowners from severe seismic events after insurance payouts and public aid. Should an M7.1 earthquake occur at shallow depth about $100 \mathrm{~km}$ north of Québec City, the report projects that only about 3\% of residential property losses would be covered by insurance. After these payments and projected government assistance, roughly $\$ 10$ billion would borne by homeowners. While a higher share of homes in BC have some earthquake insurance coverage (44\% based on 2020 CatIQ data ${ }^{2}$ ), if an M9 subduction event occurred at shallow depth off the coast of Vancouver Island, the report estimates that only about $20 \%$ of residential losses would be recouped through insurance, leaving roughly $\$ 20$ billion in uninsured losses.

The potential outcomes from earthquake disasters in these two provinces motivate the need for changes to earthquake protection programs in Canada that would achieve higher homeowner participation and fund a greater share of projected losses from future seismic events. This study examines how a proposed public-private risk pool that auto-enrolls homeowners could boost residential take-up rates for earthquake protection without requiring a compulsory government program.

\subsection{Alternative Insurance Structures for Residential Earthquake Risk}

This report estimates homeowner demand for different earthquake protection plans for representative houses in Quebec and in BC. The top panel of Table 1 details the property value, earthquake hazard, and potential damage for a house in Quebec in the first column and BC in the second column. The bottom panel of Table 1 specifies the annual price of protection and the deductible for three voluntary earthquake protection plans that covers damage to these houses. The baseline plan is "Status Quo Private”, an earthquake insurance policy covering the property value of the home with a deductible and annual premium reflecting typical policies currently sold in each province based on 2020 CatIQ data. The Quebec policy has a \$15,000 deductible (3.75\% of home value) and a \$200 annual premium while the BC policy has a $\$ 50,000$ deductible (6.67\% of home value) and a $\$ 650$ annual premium.

\section{[INSERT TABLE 1 HERE]}

\footnotetext{
${ }^{2}$ See https://public.catiq.com/
} 
The baseline plan is compared with a Public-Private Risk Pool that would cover earthquake damage above a $\$ 1,000$ deductible, with an annual premium that is lower than Status Quo Private (\$100 for Quebec, \$400 for BC). While we leave a fuller discussion of the Public-Private Risk Pool to the forthcoming ICLR report, the innovation reducing its premium and deductible is a publicly funded risk pool for the first $\$ 100,000$ in damage above the $\$ 1,000$ deductible combined with private insurance for damages over $\$ 100,000$. It is designed to provide well-defined public disaster assistance through the risk pool and incentivize more homeowners to purchase insurance so that rebuilding their house after suffering earthquake damage would be covered. The third plan, High Deductible Private, is designed to represent the private component of the Public-Private Risk Pool with the same annual premium and a \$100,000 deductible.

Our main interest is determining whether more homeowners would purchase earthquake protection through the Public-Private Risk Pool than through private insurance currently offered in Canada. Today, public post-disaster assistance in Canada is not clearly defined ex ante and is not contingent on insurance coverage. We hypothesize that the Public-Private Risk Pool will be preferred to both private coverage options due to having a lower deductible and an annual price less than or equal to either private plan. [Hypothesis H1a]

Expected utility theory would predict greater demand for the High Deductible Private plan than the lower-deductible Status Quo Private due to a lower risk premium and a decrease in substituting market-based coverage to self-insurance (Ehrlich \& Becker, 1972). However, empirical evidence on actual property and casualty insurance markets suggests that many households have a preference for lower-deductible (higher event probability) insurance plans, which is inconsistent with expected utility maximization for plausible levels of risk aversion (see e.g. Sydnor, 2010 on home insurance deductible choices) and research documenting a general tendency to prefer lower-deductible health insurance plan options in a similar experimental context (Kunreuther \& Pauly, 2021). Based on these findings, we expect to observe higher take-up of earthquake coverage for the Status Quo Private plan since it has a lower deductible than High Deductible Private and both insurance policies reflect typical pricing in the current market as shown by Hypothesis H1b.

\section{Hypotheses 1 [H1]:}

1a. A higher proportion of homeowners will choose to purchase EQ coverage when this involves participation in the proposed public-private risk pool than when it involves the status quo private coverage structure.

1b. A higher proportion of homeowners will choose to purchase EQ coverage when this involves the status quo private coverage rather than a high deductible (HD) private coverage plan. 


\subsection{Opt-Out Enrollment}

For any choice between two or more options, the default is the alternative that does not require any action by the decision maker. With respect to residential property insurance for a specific hazard like earthquake, the typical default is non-enrollment (i.e., a home insurance plan without any protection against losses from earthquake damage). The consumer could then decide whether to purchase an earthquake insurance rider (i.e., opt-in to coverage). An alternative frame would automatically enroll all homeowners in an insurance plan that covers earthquake damage with the consumer deciding whether or not to remove that aspect of coverage in return for a lower annual premium (i.e., opt-out of coverage) (Meyer and Kunreuther, 2017).

While neoclassical economic theory assumes that such a change in the default should not affect participation in a given insurance plan, empirical research has demonstrated that default options substantially influence even high stakes economic choices. In general, empirical studies show that opt-out enrollment increases take-up of an option relative to opt-in enrollment across diverse domains from health insurance prescription drug plans (Brot-Goldberg et al., 2021) to retirement saving (e.g., Madrian \& Shea, 2001; Choi et al., 2004) to organ donation (Johnson \& Goldstein, 2003). Empirical research has also shown that variation in the default plan across U.S. states also impacts the decision on what automobile insurance policy to purchase (Johnson et al., 2003). Opt-out enrollment increases the take-up of property insurance against natural disaster risk in surveys with hypothetical purchase decisions (Robinson et al., 2020). These findings motivate our hypothesis that making EQ coverage for Canadian homeowners' an opt-out feature of their home insurance rather than an additional feature that they can opt-in to would increase its take-up.

Hypothesis 2 [H2] A higher proportion of homeowners will choose to purchase EQ coverage when it is presented as a default component of their home insurance plan which they can opt-out of rather than an extra type of coverage that they can opt-in to purchasing.

\subsection{Propensity to take up earthquake protection and underlying hazard}

Given the lower likelihood of an earthquake in Quebec than BC and the small percentage of homeowners purchasing earthquake insurance in Quebec relative to those residing in BC, we anticipate Quebec respondents in our study will also be less likely to purchase private earthquake insurance or join the risk pool than $\mathrm{BC}$ respondents. We are also interested from a policy perspective in how preference for EQ insurance differs between homeowners in these two provinces when we change the default option and the nature of coverage (i.e., risk pool vs. status quo and high deductible private insurance). Given that there is greater interest in EQ insurance in BC we specify the following hypothesis: 
Hypothesis 3 [H3] A larger proportion of homeowners will purchase EQ coverage among $\mathbf{B C}$ homeowners facing the higher-hazard BC scenario relative to Quebec homeowners in the lower-hazard Quebec scenario.

\section{Methods}

We conducted a web-based survey experiment in which Canadian homeowners from Quebec and $\mathrm{BC}$ were given a hypothetical scenario where they own a house in the province in which they currently reside and asked to decide whether or not to purchase earthquake coverage in the context of a specific earthquake protection plan. To test the hypotheses described in the prior section, we randomly assigned study participants to one of six experimental conditions by varying the insurance plan and default purchase option, and compared the proportion of respondents who chose to purchase EQ coverage across these conditions. ${ }^{3}$

\subsection{Study Set-Up and Procedures}

The web-based experiment was developed and implemented on the Qualtrics online survey platform and participants were recruited through the Leger Opinion panel. Following Leger's standard procedures, email invitations without details on the study topic, were sent to panel members who owned a home in either Quebec or BC and invitees could choose to participate by following an enclosed link to the survey. As the study includes French-speaking Quebec residents and English-speaking British Columbia residents, invitees could select between these two language options on the first page of the survey.

After answering a few brief screening questions on age, homeownership, country and province of residence to confirm eligibility and completing an attention screen to make sure they were reading task instructions correctly, those participating in the experiment were asked to assume the role of someone who owns a house with a typical property value (\$400,000 in Quebec and $\$ 750,000$ in BC) in the province in which they currently lived. They were then provided with information on the likelihood of a property-damaging earthquake in their province over the next 50 years, the average damage from such an earthquake and the likelihood that their house would be destroyed. (See Appendix A for the full text of the scenarios).

\footnotetext{
${ }^{3}$ The pre-registered experimental design and analyses are available through AsPredicted at: https://aspredicted.org/blind.php?x=6y3uw5.
} 


\subsection{Experimental Design}

The study featured a between-subjects design with equal probability of assignment to one of six conditions: 3 earthquake coverage plans (status quo private, public-private risk pool, or high deductible private) x 2 default choice frames (opt-in or opt-out). Figure 1 depicts this design schematically, showing the differences in background information given to Quebec and BC participants in Panel A, randomly assigned plans in Panel B, and default assignments in Panel C.

\section{[INSERT FIGURE 1 HERE]}

Earthquake Coverage Plans: Participants made a purchase choice for one of the three possible insurance coverage plans summarized in Table 1, Panel B: The Status Quo Private plan reflects typical current residential earthquake insurance policies in the Canadian private market with a moderate deductible of $\$ 15,000$ for Quebec and \$50,000 for BC with associated premiums of $\$ 200$ and \$650, respectively. The Public-Private Risk Pool has lower annual premiums (\$100 in Quebec, \$400 for BC) and a low annual deductible of $\$ 1,000$, after which the Canadian government covers the first $\$ 100,000$ in damage combined with private market insurance coverage for damages over \$100,000. The High Deductible Private plan offers only insurance covering damages over $\$ 100,000$ with the same annual premium as the public-private structure.

After respondents decided whether to purchase earthquake protection under a given insurance plan, some were then asked to consider a second plan and determine whether they wanted this type of coverage. Specifically, participants who were initially asked whether they wanted to participate in the Public-Private Risk Pool if this was their only choice were then asked if they would purchase Status Quo Private coverage if this were the only available plan. Those asked initially whether they would purchase Status Quo Private coverage were then asked if they would want protection from the Public-Private Risk $\mathrm{Pool}$ if this were the only plan available to them. Our prespecified analysis plan was to pool data from these two choices if there were no order effects. We did observe order effects, so these additional choices are not included in our primary analysis.

Default Choice Frame: Participants were randomly assigned to one of two default frames: In the Opt-in frame, participants read that they do not currently have earthquake coverage on their house and could choose whether or not to purchase coverage. In the Opt-out frame, participants read that they currently have earthquake coverage and could choose whether to opt out of this insurance and face a lower premium. Our main outcome measure is the proportion of participants in each experimental condition who chose to purchase earthquake protection. 


\subsection{Post-Choice Survey Measures}

After making their insurance purchase decisions based on the relevant scenarios and plans, participants were directed to a post-choice survey module where the following measures of participants' perception of the earthquake hazard were obtained:

- an estimate of the cost to the homeowner if the property was damaged by an earthquake (either a dollar estimate, or "I did not think of a damage estimate"),

- a measure of how worried a participant would be about experiencing earthquake damage to their hypothetical house over the next 50 years on a scale from 1 (not at all worried) to 6 (extremely worried),

- an estimate of the likelihood that the house in the scenario would be damaged by an earthquake in the next 50 years ranging from "Less than a 1 in 1 million chance" to "Greater than a 1 in 10 chance" with 5 categories between these two extreme probability estimates. For respondents who selected one of the five intermediate likelihood ranges, we also elicited a fine-grained estimate of the likelihood within that range using a sliding scale with the lowest and highest probabilities at the two ends of the slider.

We also elicited the following background characteristics on the respondents:

- whether they had previously experienced earthquake damage to a house in which they lived (yes/no and the most recent year if an earthquake was experienced),

- whether they had previously purchased earthquake insurance

- their risk-taking tendency using a 10-point Likert scale ranging from 1 (extremely unwilling to take risks) to 10 (extremely willing to take risks).

- socio-economic characteristics: gender, highest level of school completed, categorical range of prior-year household income and their 6-digit postal code.

After respondents completed the survey, we determined a measure of their actual home's seismic hazard based on Peak Ground Acceleration (PGA) from the 2015 Geological Survey of Canada using the first three digits of the participant's postal code. The houses were assigned to a value on a seven-point scale with PGA ranging from $0.0 \mathrm{~g}$ (lowest measure) to $0.7 \mathrm{~g}$ or greater (highest measure) based on $0.1 \mathrm{~g}$ intervals where $g$ is gravitational acceleration. 


\subsection{Participant Sample and Recruitment}

Using panelists from the Leger survey, 1,201 Quebec homeowners and 1,199 BC homeowners were recruited for the experiment. ${ }^{4}$ Participants were assigned randomly to one of the six conditions at the provincial level. Table 2 summarizes the demographic characteristics and background of the full sample in the leftmost column and the two provincial subsamples in the next two columns. This table offers some insight into the generalizability of findings from our sample to the broader population of Canadian homeowners in the two provinces. Overall, 53\% of the sample reported 2020 household income of over $\$ 80,000$, which is broadly consistent with 2018 median household incomes of roughly $\$ 84,000$ in Quebec and \$88,000 in $\mathrm{BC}^{5}$. As expected, given home-buying patterns, our sample skews substantially older than the total population average of around 42 years for both provinces in 2020 data. ${ }^{6}$ The average age in our sample is 57 years, quite consistent with a 2018 census study on housing in three provinces showing an average age of 56 among residential property owners in British Columbia. ${ }^{7}$

The last two rows of Table 2 show that $4 \%$ of the overall sample reported having experienced earthquake damage to a home in which they lived (3\% among Quebec and 4\% among BC respondents) and 34\% reported that they currently have or previously had earthquake insurance. While the latter question does not map perfectly to data on current take-up (as it includes prior coverage at any residence), we can gain insight into differences between the provinces by comparing these statistics. Consistent with current CatIQ data showing a much higher share of homeowners with some EQ coverage in BC (44\%) than in Quebec (3\%), in our sample BC respondents were significantly more likely to report having purchased earthquake insurance (50\%) compared with only 19\% of the Quebec subsample. ${ }^{8}$

[INSERT TABLE 2 HERE]

\footnotetext{
${ }^{4}$ This targeted sample size of $n=400 \times 6$ experimental conditions was determined based on a power analysis with $81 \%$ power to detect a true difference in take-up across two conditions with an effect size of 0.20 or more. Separate quotas for each province ensured comparable sample sizes in each condition.

${ }^{5}$ Census Table: 11-10-0009-01 accessed at https://www150.statcan.gc.ca/t1/tbl1/en/tv.action?pid=1110000901\&pickMembers\%5B0\%5D=1.9\&cubeTimeFram e.startYear=2014\&cubeTimeFrame.endYear=2018\&referencePeriods $=20140101 \% 2 \mathrm{C} 20180101$

${ }^{6}$ See Census Table 17-10-0005-01 accessed at https://www150.statcan.gc.ca/t1/tbl1/en/tv.action?pid=1710000501\&pickMembers\%5B0\%5D=1.6\&pickMembers\% $\underline{\text { 5B1\%5D }=2.1 \& \text { cubeTimeFrame. } \text { startYear }=2016 \& \text { cubeTimeFrame.endYear=2020\&referencePeriods }=20160101 \% 2}$ C20200101

7 “Homeownership, income, and residential property values.” https://www150.statcan.gc.ca/n1/pub/46-280001/2019001/article/00002-eng.htm

${ }^{8} \mathrm{~A}$ chi-square test of proportions revealed that there was a significant difference between the purchase rate in the two provinces $(\mathrm{p}<0.01)$.
} 
Appendix Figure A1 illustrates this difference between the provinces in greater detail by plotting reported prior coverage among respondents and CatIQ average current coverage across respondent 3-digit postal codes ordered by increasing seismic hazard (PGA) and within each province. This plot also shows the larger gap between Quebec self-reports (dashed green) and actual province-wide take-up (solid green) than the same comparison for BC (dashed and solid blue). It further indicates that the gap between these measures in Quebec does not vary across respondents in postal codes with varying objective seismic hazard. However, we note that this difference between the correspondence of Quebec survey reports and actual take-up likely reflects broader confusion about EQ coverage than in BC. For example, a 2015 Insurance Bureau of Canada survey showed that roughly a third of the surveyed Quebec homeowners believed their policy already covered earthquakes relative to a $4 \%$ actual coverage rate at the time. ${ }^{9}$

\section{Results}

\subsection{Overview of Results}

The data from the web-based experiment were analyzed using logistic regressions. Our basic model (M1) predicts EQ take-up as a function of indicator variables capturing random assignment to one of the two default conditions, to one of the three insurance plans, and whether the participant lived in British Columbia $(\mathrm{BC}=1)$ or Quebec $(\mathrm{BC}=0)$. We estimate the following equation for the full sample, pooling both provinces:

$$
\ln \frac{p}{1-p}=\beta_{0}+\beta_{1} * \text { optout }+\beta_{2} * \text { riskpool }+\beta_{3} * \text { hdprivate }+\beta_{4} * B C
$$

where $p$ captures the probability of purchasing EQ coverage so that $p / 1-p$ is an odds ratio. The base conditions are opt-in for the default frame (optout=0) and status quo private for the insurance plan ( riskpool=0, hdprivate $=0$ ).

To assess the robustness of the estimated effects of M1 to the inclusion of non-experimental controls, logistic regressions were undertaken for two additional models. M2 is identical to M1 with additional variables based on post-choice survey responses in the last term:

$$
\ln \frac{p}{1-p}=\beta_{0}+\beta_{1} * \text { optout }+\beta_{2} * \text { riskpool }+\beta_{3} * \text { hdprivate }+\beta_{4} * B C+\gamma^{\prime} X \quad(M 2-M 3)
$$

where $X$ is a vector of the following socio-economic characteristics of the respondents (age, gender, university education, and whether reported household income is above the sample-median of $\$ 80 \mathrm{k}$ ), selfassessed degree of risk-taking propensity (1-10 increasing), prior experience of residential earthquake damage $(1,0)$, and currently or previously purchasing earthquake insurance $(1,0)$.

\footnotetext{
${ }^{9}$ See “Quake Coverage” Canadian Underwriter, October 14, 2016 at https://www.canadianunderwriter.ca/features/quake-coverage/
} 
M3 is identical to M2 with one additional control variable in $X$ that reflects the seismic hazard denoted by PGA at the respondent's actual home post code. The PGA variable examines whether differences in respondents' earthquake hazard in the house in which they are currently living affects their propensity to purchase insurance in the scenarios presented to them in the web-based experiment.

For each of these three models, we also estimated two logistic regressions for the subsamples of respondents from Quebec and from BC (Note: the coefficient $\beta_{4}$ in both equations drops out in these analyses). Table 3 presents the results from this series of regressions, with the three columns showing exponentiated coefficient estimates — that is, odds ratios—-for M1, M2, and M3, respectively, for the fullsample models (columns 1-3) for the Quebec subsample (columns 4-6), and for the BC subsample (columns 7-9).

\section{[INSERT TABLE 3 HERE]}

To facilitate the comparison of the main estimates of interest across regression models, Figure 2 plots the odds ratio estimates of the opt-out default frame, insurance plan structures relative to the baseline of Status Quo Private, and respondent’s province with 95\% confidence intervals for M1, M2 and M3 (M1 estimates denoted by blue circles, M2 by red diamonds, and M3 by green triangles). The dashed vertical line at an odds ratio of 1 corresponds to no difference in the take-up outcome as a function of the variables in the logistic regression. The high odds ratios for the Public-Private Risk Pool indicates that respondents strongly preferred this insurance plan over the other two plans. The high odds-ratio for the default frame indicates that there was an increase in EQ insurance purchase if respondents were told they could opt-out of the plan rather than asking them whether they wanted to opt-in by purchasing the plan. $\mathrm{BC}$ respondents were more likely to purchase EQ insurance than those residing in Quebec and there was a slight preference for the HD Private Coverage than Status Quo Private.

\section{[INSERT FIGURE 2 HERE]}

\subsection{Evidence on Earthquake Coverage Take-Up Hypotheses}

Below, we discuss the evidence relating to each of our hypotheses in greater detail.

H1a. Risk Pool Take-Up > Status Quo Private Take-Up. The results of the study strongly support H1a that Risk Pool-Private Coverage will be more appealing to homeowners than Status Quo Private. As shown in the bottom panel of Figure 3, only 44\% of participants assigned to a Status Quo Private plan purchase earthquake coverage compared to $66 \%$ of those assigned to the Risk Pool-Private Coverage plan. This difference is reflected in the logistic regressions coefficients for M1 (column 1) in Table 3. 
Controlling for the choice frame and province, assignment to the risk pool is associated with being 2.51 times as likely to take-up of EQ coverage than if a participant was assigned to the status quo $(\mathrm{p}<0.01)$. The full-sample models with additional controls, M2 (column 2) and M3 (column 3), show slightly higher but qualitatively similar odds ratio estimates.

The provincial models for Quebec (columns 4-6) and BC (columns 7-9) reveal that homeowners in $\mathrm{BC}$ are predicted to be at least 2.90 times as likely to take-up insurance coverage with the risk pool relative to the status quo, while those in Quebec are at least 2.15 times as likely to follow suit $(\mathrm{p}<0.01$ for all comparisons).

\section{H1b. Status Quo Private Take-Up > High Deductible (HD) Private Take-Up}

Pooling respondents from both provinces (M1) in Figure 3 reveals that there is no evidence of a statistically significant difference in take-up of earthquake coverage between the two private coverage plans with 44\% take-up of those assigned to Status Quo Private and 48\% take-up for those assigned to the HD Private Coverage plan. Consistent with this finding, M1 (Table 3, column 1) shows a slightly higher odds ratio of take-up for the HD Private Coverage plan compared to Status Quo Private but the difference is not statistically significant (odds ratio $=1.16$, ns). This result is similar for M2 and M3.

\section{[INSERT FIGURE 3 HERE]}

When we compare the two private insurance plans within the Quebec and BC subsamples, as shown in Figure 4 (Panels A and B) there are very different effects. With respect to the Quebec sample (Panel A), a much larger proportion of homeowners preferred the Status-Quo Private (58\%) than HD Private Coverage (36\%) in the opt-out conditions and there was a slight increase in preference for $H D$ Private Coverage in the opt-in condition (30\% vs 36\%). On the other hand, in the British Columbia sample (Panel B), there was a strong preference for HD Private Coverage for participants in the opt-in condition (65\% vs $43 \%$ ) and a weaker preference in the opt-in condition (48\% vs $40 \%$ ).

\section{[INSERT FIGURE 4 HERE]}

Turning to the logistic regressions (Table 3), the basic model (column 4) yields significantly lower predicted odds of take-up for those assigned to HD Private Coverage relative to Status Quo Private ( 0.71 odds ratio, $\mathrm{p}<0.05$ ), which is consistent with $H 1 b$. In contrast, column 7 estimating the same model on the BC subsample shows $84 \%$ greater likelihood (odds ratio $=1.84, \mathrm{p}<0.01$ ) of taking up the HD plan relative to the status quo plan, contrary to $H 1 b$. 
BC respondents' greater interest in a high deductible plan than the Quebec respondents may relate to ways the price menus differ in the two provinces. First, their reactions may stem from BC respondents perceiving the $\$ 100,000$ deductible as being a smaller proportion of the BC scenario's typical home value $(\$ 750,000)$ than the typical home in the Quebec scenario $(\$ 400,000)$. Another potential reason for this difference in relative preferences for the status quo and a high deductible plan for the two provinces is the dramatic 567\% increase in the deductible for Quebec ( $\$ 15 \mathrm{k}$ to $\$ 100 \mathrm{k}$ ) and only a 100\% increase in the deductible for BC respondents' (\$50k to \$100k). Third, affordability concerns may have a larger impact on BC respondents' relative preference for the cheaper High Deductible plan since respondents have similar actual incomes in both provinces, but BC respondents face steeper price increases from adding EQ coverage to a $\$ 1,300$ cost of coverage for other hazards in their scenario (50\% price increase for Status Quo, 30\% for High Deductible). In contrast, Quebec respondents face more modest price increases relative to the $\$ 1000$ premium for other hazards (20\% price increase for Status Quo, $10 \%$ for High Deductible plan).

H2: Opt-Out Take-Up > Opt-In Take-Up. Consistent with H2, participants assigned to an opt-out default are significantly more likely to take up earthquake coverage than those assigned to an opt-in default. As shown in the dashed horizontal reference lines in the first panel of Figure 4, 58\% of participants in the opt-out conditions $(\mathrm{N}=1,260)$ decide to take-up coverage, $11 \%$ higher than the $47 \%$ take-up rate in the opt-in condition $(\mathrm{N}=1,140)$. Turning to our main logistic regression model in column 1 of Table 3 where we are separately controlling for assigned plan structure and home province, we estimate an odds ratio of $1.64(\mathrm{p}<0.01)$ for opt-out, indicating that a participant is $64 \%$ more likely to take up the coverage if they are assigned to an opt-out condition compared to an opt-in condition. The subsample models show similar estimated effects within each province, with slightly larger estimated effects for Quebec (columns 4-6: 1.80-1.81 odds ratios) than BC (columns 7-9: 1.40-1.49 odds ratios).

\subsection{Non-Experimental Predictors of Earthquake Coverage Take-Up}

H3: British Columbia (BC) take-up > Quebec take-up. As hypothesized, there is a lower take-up of earthquake coverage in the experiment among Quebec respondents overall (47\%) than among BC respondents (58\%), pooling across the experimental conditions as shown in Figure 3. In our main estimate, the logistic regression model controlling for experimental conditions (Table 3, column 1) shows that a BC participant is predicted to be $54 \%$ more likely to purchase coverage relative to a Quebec participant assigned to the same condition (1.54 odds ratio, $\mathrm{p}<0.01$ ).

In addition to offering robustness checks on our experimental design effects, the models (M2 and M3) that include non-experimental controls provide insight into relationships between respondent 
characteristics and insurance take-up choices. Of particular interest, we can look at how variation in reallife experiences of earthquake hazard across participants relate to propensity to take up insurance in the experiment. As shown in Table 3 columns 2-3, M2 and M3 reveal that prior earthquake damage and purchase of earthquake insurance are associated with a higher propensity to take-up coverage in the experiment (odds ratios $=2.26-2.98$, p's $<0.01$ ) with a much higher odds ratio in BC than in Quebec, as one might anticipate given that more severe earthquakes have occurred there in recent memory and more commonly felt events may offer physical reminders increasing the salience of the threat.

M3 reveals that the seismic hazard measure for respondents' home postal codes also predicts likelihood of take-up in the experiment. Specifically, we see that a 0.1 unit increase in the Peak Ground Acceleration (PGA) measure that captures variation in earthquake hazard across postal codes is associated with a $24 \%$ increase in the likelihood of purchasing earthquake coverage in the experiment. Interestingly, the estimate for BC in the full-sample models is still significant, with modestly attenuated magnitude when moving from the basic model to those in columns 2-3 where the additional controls capture the higher earthquake hazard for BC respondents and their greater likelihood of prior earthquake experience and current or prior earthquake insurance coverage. This indicates that homeowners facing the same physical hazard in BC and Quebec behave differently. Goda et al. (2020) investigated the relationship between earthquake insurance take-up rates in Canada and seismic risk indicators. Their analysis revealed that take-up rates in BC are proportional to earthquake risk levels while those in Quebec are consistently low irrespective of exposed hazard and risk levels.

We can compare the amount of variation in take-up decisions explained by the physical hazard measure relative to other variations between provinces by looking at the increase in pseudo- $\mathrm{R}^{2}$ when moving from a model controlling only for the experimental condition (pseudo- $\mathrm{R}^{2}=.038$ ) and adding the control for PGA (pseudo- $\mathrm{R}^{2}=.046$ ) and then also for province (pseudo- $\mathrm{R}^{2}=.057$ ). ${ }^{10}$ This exercise indicates that each measure explains roughly one additional percent of variation in take-up decisions, implying that other provincial differences are as important in influencing take-up decisions as geographic variation in seismic hazard. These other differences between the provinces could be due to homeowners' risk perceptions, expectations about public disaster assistance, possibly exacerbated by decision-making heuristics like "herding” behavior in the province.

Consistent with economic theory, our 10-point survey measure of risk preference shows that a one unit increase toward the risk-loving end of the scale is associated with about a $10 \%$ lower chance of taking up insurance. ${ }^{11}$ There is no evidence of significant differences in take-up by gender, age, or

\footnotetext{
${ }^{10}$ Pseudo- $\mathrm{R}^{2}$ is a model statistic between 0 and 1 interpretable as the share of total dependent variable variation in the sample explained by that model

11 The risk-taking measure is entered as a continuous linear measure in the models presented.
} 
household income, though we do see that respondents with a university degree are modestly more likely to purchase the insurance than their counterparts with lower education (odds ratio $=1.24-1.27$ ).

\subsection{Order Effects: Evidence from Secondary Coverage Choices}

The estimates discussed above incorporate the decisions of only the primary insurance coverage choice because we observed differentially lower take-up of Status Quo Private among respondents who considered this plan after determining whether they want to participate in the Public-Private Risk Pool. This order effect is depicted in Figure 5, which compares the average share of respondents purchasing earthquake coverage in primary choices in light gray bars relative to secondary choices in dark gray bars. Here we see that only $38 \%$ of respondents purchase status quo insurance after considering the risk pool option, a significantly lower share than the $44 \%$ who take up the status quo insurance option when this is the first plan described to them (i.e., the null hypothesis of equal proportions is rejected with $\mathrm{p}<0.01$ ). In contrast to this finding, there is no order effect on take-up of the risk pool option when it is presented as either a first choice primary (66\%) or secondary choice (65\%) (i.e., $p=0.50$ ).

\section{[INSERT FIGURE 5 HERE]}

The negative order effect for the less popular Status Quo Private plan is consistent with prior research comparing choices made when the decision maker can jointly evaluate two options relative to evaluating each of these options separately. Studies indicate that the joint evaluation mode tends to lead to greater differences in preference between two options than two separate evaluations of each option because it is easier for decision-makers to evaluate attributes that vary across options (Hsee et al., 1999). This literature also shows that for unfamiliar domains, the ability to jointly evaluate options produces a larger difference. Given that earthquake insurance is unfamiliar to many homeowners-particularly those outside of British Columbia-increasing consumer awareness of the possibility of a Public-Private Risk Pool would increase preferences for this option over the Status Quo Private, which is what we found. The negative order effect on the status quo plan and absence of a positive order effect on the Public-Private Risk Pool plan suggests that learning that Status Quo Private is a relatively bad deal first is more likely to influence demand for the Public-Private Risk Pool than learning that the risk pool option is a relatively good deal first. This behavior is consistent with loss aversion where losses loom larger than equallysized) gain (Kahneman and Tversky, 1979; see O’Donoghue \& Sprenger, 2018 for a detailed review of the economic literature on reference-dependent preferences). 


\section{Conclusions and Policy Implications}

Homeowners in Quebec and British Columbia were given the opportunity to purchase protection against earthquake losses in a web-based choice experiment where they were presented with the following options: a typical private insurance plan in the current market, a high deductible private plan, and a proposed public-private risk pool. The default frame was changed so the homeowner could either opt-in by purchasing this coverage or opt-out of being given this protection and receiving a premium discount. Comparing earthquake coverage that resembles the current private market offerings for Canadian homeowners to a unified public-private risk pool dramatically increases the percentage of homeowners demanding earthquake protection. Controlling for other variations in the experiment, when a participant is assigned to the Public-Private Risk Pool rather than the Status Quo Private insurance plan, the likelihood of purchasing earthquake protection increases by $151 \%$ (odds ratio 2.51). Furthermore, opt-out enrollment substantially increases take-up of earthquake protection relative to opt-in enrollment. We estimate that the opt-out frame leads to a likelihood greater than 1.6 of purchasing coverage relative to the opt-in frame when given the same plan structure. This positive effect of opt-out enrollment does not differ significantly between the two provinces. Taken together these findings implies that the share of homeowners choosing earthquake protection in our full sample doubles from $35 \%$ under the status quo structure with opt-in enrollment to $71 \%$ under the proposed public-private risk pool with opt-out enrollment.

The results of this study have two important implications for policymakers and insurance practitioners interested in encouraging more homeowners to purchase earthquake protection against future losses. First, offering the proposed public-private risk pool that provides homeowners full coverage of damages after a \$1,000 deductible for a discounted annual price (\$100 for Quebec, \$200 for BC) subsidized by the publicly funded risk pool for the first $\$ 100,000$ in damages with private insurance covering additional losses would significantly increase the demand for earthquake protection relative to typical existing private insurance plans in both provinces. Second, independent of the available plan, providing homeowners with coverage against earthquake losses and allowing them to opt-out of this protection is likely to significantly increase their interest in protecting their house against future financial losses than if homeowners were asked if they would like to purchase insurance to cover earthquake losses to their property. 
Table 1. Earthquake and Insurance Information in Experiment Choice Task

\begin{tabular}{|c|c|c|}
\hline & Quebec & British Columbia \\
\hline \multicolumn{3}{|l|}{ Panel A. Earthouake Risk Information } \\
\hline \multicolumn{3}{|l|}{ Constant across experimental conditions } \\
\hline \multirow{2}{*}{$\begin{array}{l}\text { Likelihood of damaging earthquake, } 50 \text { yrs. } \\
\text { Average damage amount | damage }\end{array}$} & 1 in 10 & 1 in 3 \\
\hline & $\$ 115,000$ & $\$ 115,000$ \\
\hline Likelihood of full house value lost | damage & 1 in 13 & 1 in 19 \\
\hline Full value of house & $\$ 400,000$ & $\$ 750,000$ \\
\hline \multicolumn{3}{|l|}{ Panel B. Earthquake Coverage and Prices } \\
\hline \multicolumn{3}{|l|}{ Varied across experimental conditions } \\
\hline \multicolumn{3}{|l|}{ Status Quo Private Coverage } \\
\hline Annual Price & $\$ 200$ & $\$ 650$ \\
\hline Deductible & $\$ 15,000$ & $\$ 50,000$ \\
\hline \multicolumn{3}{|l|}{ Public-Private Risk Pool } \\
\hline Annual Price & $\$ 100$ & $\$ 400$ \\
\hline Deductible & $\$ 1,000$ & $\$ 1,000$ \\
\hline \multicolumn{3}{|l|}{ High Deductible Private Coverage } \\
\hline Annual Price & $\$ 100$ & $\$ 400$ \\
\hline Deductible & $\$ 100,000$ & $\$ 100,000$ \\
\hline
\end{tabular}


Table 2. Summary of Sample Overall and by Province

\begin{tabular}{|c|c|c|c|c|}
\hline & \multirow{2}{*}{$\frac{\text { Overall Mean }}{\text { All }}$} & \multicolumn{2}{|c|}{ Means by Province } & \multirow{2}{*}{$\frac{\text { Difference in means }}{\text { p-value, chi-sq or t-tes }}$} \\
\hline & & Quebec & British Columbia & \\
\hline \multicolumn{5}{|l|}{$\underline{\text { Sample size }}$} \\
\hline $\mathrm{N}$ & 2400 & 1201 & 1199 & -- \\
\hline \multicolumn{5}{|l|}{ Demographics } \\
\hline Male $[1,0]$ & 0.47 & 0.46 & 0.48 & 0.35 \\
\hline Age [Years] & 57.3 & 55.8 & 58.7 & $<0.01$ \\
\hline University degree $[1,0]$ & 0.49 & 0.45 & 0.52 & $<0.01$ \\
\hline HH income $\geq \$ 80 \mathrm{k}[1,0]$ & 0.53 & 0.54 & 0.52 & 0.29 \\
\hline \multicolumn{5}{|c|}{ EQ Damage and Insurance Experience } \\
\hline Have Had EQ Damage [1,0] & 0.04 & 0.03 & 0.04 & 0.19 \\
\hline Have Had EQ Insurance $[1,0]$ & 0.34 & 0.19 & 0.50 & $<0.01$ \\
\hline
\end{tabular}


Table 3. Logistic regressions predicting EQ take-up [1,0] by experimental factor (default, structure)

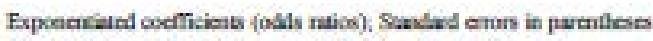

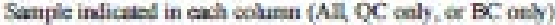

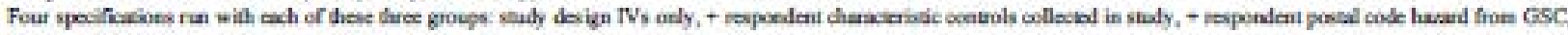
Remeves FQ danseg and insuratce print experience from (3)

\begin{tabular}{|c|c|c|c|c|c|c|c|c|c|}
\hline & \multicolumn{3}{|c|}{ Full Saraple } & \multicolumn{3}{|c|}{ Oucbex Sulsample } & \multicolumn{3}{|c|}{ BC. Sulvample } \\
\hline & (1) & (2) & (3) & (4) & (5) & (6) & $(7)$ & (8) & (9) \\
\hline \multicolumn{10}{|l|}{ Fuprimanal Fashers (Level indicatces) } \\
\hline \multicolumn{10}{|l|}{ Defink (Mese = ugl-ai) } \\
\hline Optout & $\begin{array}{c}1.64 * * * \\
(0.14)\end{array}$ & $\begin{array}{c}153 *+* \\
(0.14)\end{array}$ & $\begin{array}{c}1.59 *+* \\
(0.14)\end{array}$ & $\begin{array}{c}181 * \cdots \\
(0.22)\end{array}$ & $\begin{array}{c}180 * * * \\
(0.2)\end{array}$ & $\begin{array}{c}1.81 *+* \\
(0.22)\end{array}$ & $\begin{array}{c}1.49 * * \\
(0.18)\end{array}$ & $\begin{array}{c}1.40 *+* \\
(0.18)\end{array}$ & $\begin{array}{c}1.41 * * \\
(0.18)\end{array}$ \\
\hline \multicolumn{10}{|l|}{ Seracaure of concrayt (hase = staus qua private) } \\
\hline Rises Pool & $\begin{array}{c}251 * * * \\
(0.26)\end{array}$ & $\begin{array}{c}260 *+* \\
(0.28)\end{array}$ & $\begin{array}{c}259 *+* \\
(0.28)\end{array}$ & $\begin{array}{c}2.15 * * * \\
(0.31)\end{array}$ & $\begin{array}{c}2.21^{* * * *} \\
(0.33)\end{array}$ & $\begin{array}{c}2.22 * * \\
(0.33)\end{array}$ & $\begin{array}{c}2.91 * * \\
(0.43)\end{array}$ & $\begin{array}{c}2.92 * * * \\
(0.46)\end{array}$ & $\begin{array}{c}290^{* 4 *} \\
(0.46)\end{array}$ \\
\hline Hiph Deductilie Private & $\begin{array}{c}1.16 \\
(0.12)\end{array}$ & $\begin{array}{c}1.11 \\
(0.12)\end{array}$ & $\begin{array}{c}1.12 \\
(0.12)\end{array}$ & $\begin{array}{l}0,71^{* *} \\
(0.10)\end{array}$ & $\begin{array}{l}0.69 * * \\
(0.10)\end{array}$ & $\begin{array}{l}0.704 \cdot \\
(0.11)\end{array}$ & $\begin{array}{c}1.84 * * \\
(0.27)\end{array}$ & $\begin{array}{c}1.75 *+* \\
(0.27)\end{array}$ & $\begin{array}{c}1.73 * * * \\
(0.27)\end{array}$ \\
\hline \multicolumn{10}{|l|}{ Pessince in scoenario } \\
\hline Brialh Columbia (BC-1, Quelose-0) & $\begin{array}{c}154 * * * \\
(0.13)\end{array}$ & $\begin{array}{l}1.25 * 4 \\
(0.12)\end{array}$ & $\begin{array}{c}1.33 * * * \\
(0.13)\end{array}$ & & & & & & \\
\hline \multicolumn{10}{|l|}{ 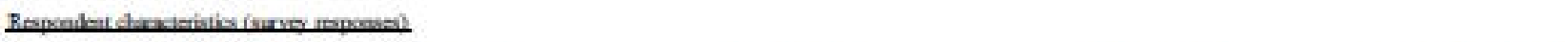 } \\
\hline Price experiance of $\mathrm{BQ}$ dunape $[1,0]$ & & $\begin{array}{l}298 * * 6 \\
(0.81)\end{array}$ & $\begin{array}{l}2.96 * \cdots \\
(0.80)\end{array}$ & & $\begin{array}{l}2.01 * \\
(0.75)\end{array}$ & $\begin{array}{l}1.97 * \\
(0.73)\end{array}$ & & $\begin{array}{c}3.91 * * \\
(1.61)\end{array}$ & $\begin{array}{c}3.94 * 0 . \\
(1.63)\end{array}$ \\
\hline Prisor experience purchasing $E Q$ insuratice $[1,0]$ & & $\begin{array}{l}2.40^{* * .} \\
(0.24)\end{array}$ & $\begin{array}{l}2.26 * \cdots \\
(0.23)\end{array}$ & & $\begin{array}{c}153 * * * \\
(0.25)\end{array}$ & $\begin{array}{c}1.54 * \cdots \\
(0.25)\end{array}$ & & $\begin{array}{c}3.37 *+* \\
(0.44)\end{array}$ & $\begin{array}{c}3.16 *+. \\
(0.43)\end{array}$ \\
\hline Rik-taking lexalency, increaving (1-7) & & $\begin{array}{l}0.87 * * . \\
(0.02)\end{array}$ & $\begin{array}{l}0.87 *+* \\
(0.02)\end{array}$ & & $\begin{array}{c}0.89 *+* \\
(0.03)\end{array}$ & $\begin{array}{c}0.88+\cdots \\
(003)\end{array}$ & & $\begin{array}{c}0.85 *+* \\
(0.03)\end{array}$ & $\begin{array}{c}0.85 * 4 . \\
(0.03)\end{array}$ \\
\hline Male $[1,0]$ & & $\begin{array}{l}0.94 \\
(0.09)\end{array}$ & $\begin{array}{l}0.93 \\
(0.09)\end{array}$ & & $\begin{array}{l}0.75 * * \\
(0.10)\end{array}$ & $\begin{array}{l}0.76 * * \\
(0.10)\end{array}$ & & $\begin{array}{l}1.19 \\
(0.16)\end{array}$ & $\begin{array}{l}1.18 \\
(0.16)\end{array}$ \\
\hline Univesily degrex $[1,0]$ & & $\begin{array}{l}1.27 * * . \\
(0.11)\end{array}$ & $\begin{array}{l}1.24 * * \\
(0.11)\end{array}$ & & $\begin{array}{l}1.33 * * \\
(0.17)\end{array}$ & $\begin{array}{l}1.30 \% \\
(0.16)\end{array}$ & & $\begin{array}{c}1.19 \\
(0.16)\end{array}$ & $\begin{array}{l}1.17 \\
(0.16)\end{array}$ \\
\hline HH incone above \$\$8k (cunple median) $[1,0]$ & & $\begin{array}{r}1.09 \\
(0.10)\end{array}$ & $\begin{array}{c}1.07 \\
(0.10)\end{array}$ & & $\begin{array}{l}1.15 \\
(0.15)\end{array}$ & $\begin{array}{l}1.13 \\
(0.15)\end{array}$ & & $\begin{array}{c}1.02 \\
(0.14)\end{array}$ & $\begin{array}{c}1.01 \\
(0.14)\end{array}$ \\
\hline Age (10-year bins, lase- $<30)$ & & $\begin{array}{r}1.00 \\
(0.00)\end{array}$ & $\begin{array}{c}1.00 \\
(0,00)\end{array}$ & & $\begin{array}{l}1.01 \\
(0,00)\end{array}$ & $\begin{array}{c}1.01 \\
(0.00)\end{array}$ & & $\begin{array}{c}0.98 * * * \\
(0,00)\end{array}$ & $\begin{array}{c}0.99 * 4 * \\
(0.00)\end{array}$ \\
\hline \multicolumn{10}{|l|}{ Repocadear posi oode sebanic heuand } \\
\hline $\mathrm{N}$ & 2400 & 2397 & 2395 & 1201 & 1200 & 1198 & 1199 & 1197 & 1197 \\
\hline Preudo- $\mathrm{R}^{2}$ & 0.045 & 0.093 & 0.056 & 0.051 & 0,077 & 0080 & 0.039 & 0.125 & 0.127 \\
\hline
\end{tabular}

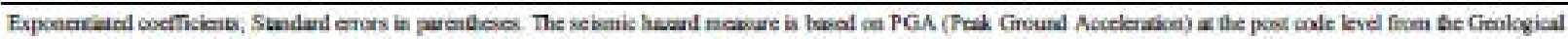

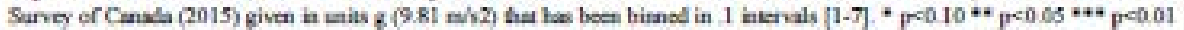




\section{Figure 1. Experimental Design}

\section{Panel A. Scenario Geographic Setting}

Study participants are assigned to one of two geographic settings for the scenario settings to match the province where they own a home (either BC or Quebec). The specified risk and home value information varies as described below.

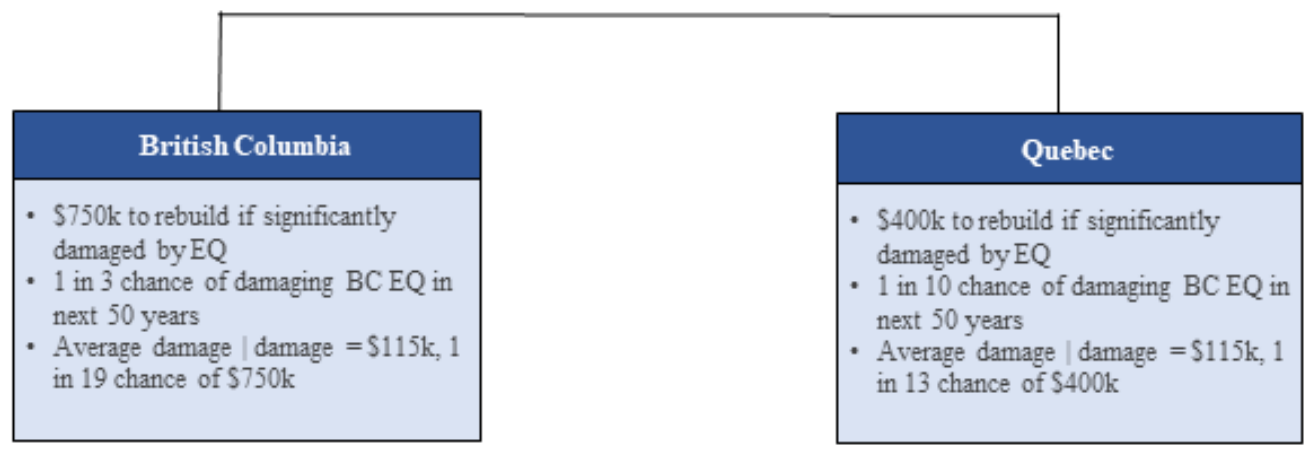

Panel B. Experimental Variation in Earthquake Protection Structure

Participants randomized to one of three distinct structures of EQ protection offered that vary in role of the public \& private sector, deductible, and premium

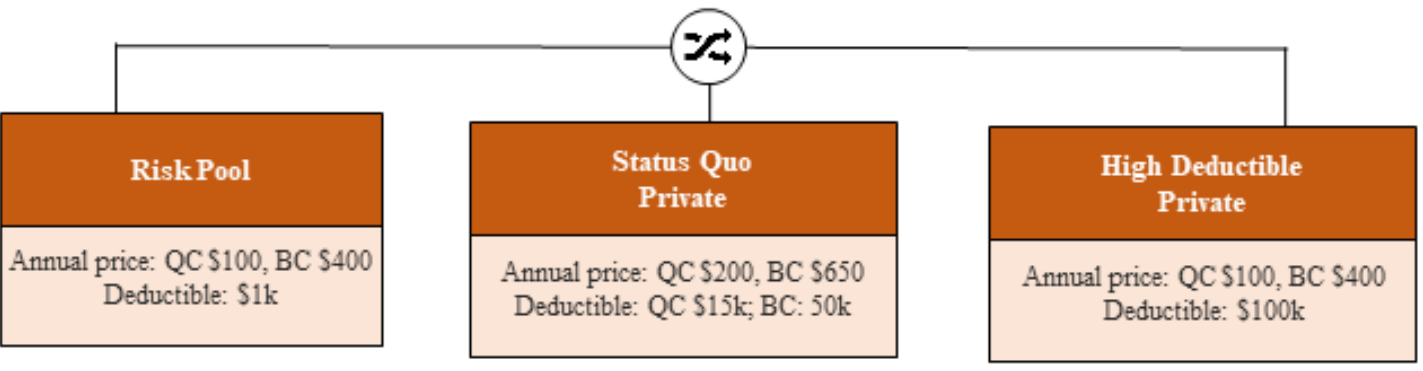

Panel C. Experimental Variation in Default Purchase Option

Respondents randomized to purchase choice with default of purchasing (opt-out) or of not purchasing (opt-in)

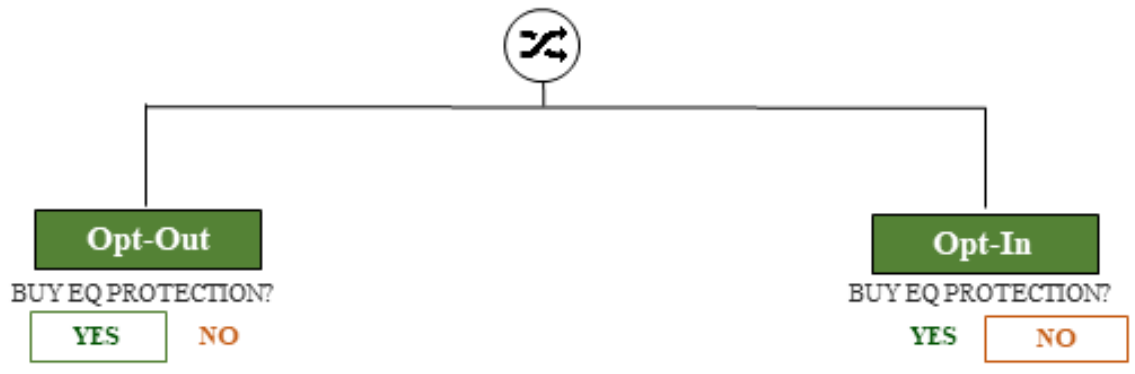


Figure 2. Logistic Regression Odds Ratio Estimates Across Models Predicting EQ

\section{Coverage Take-Up}

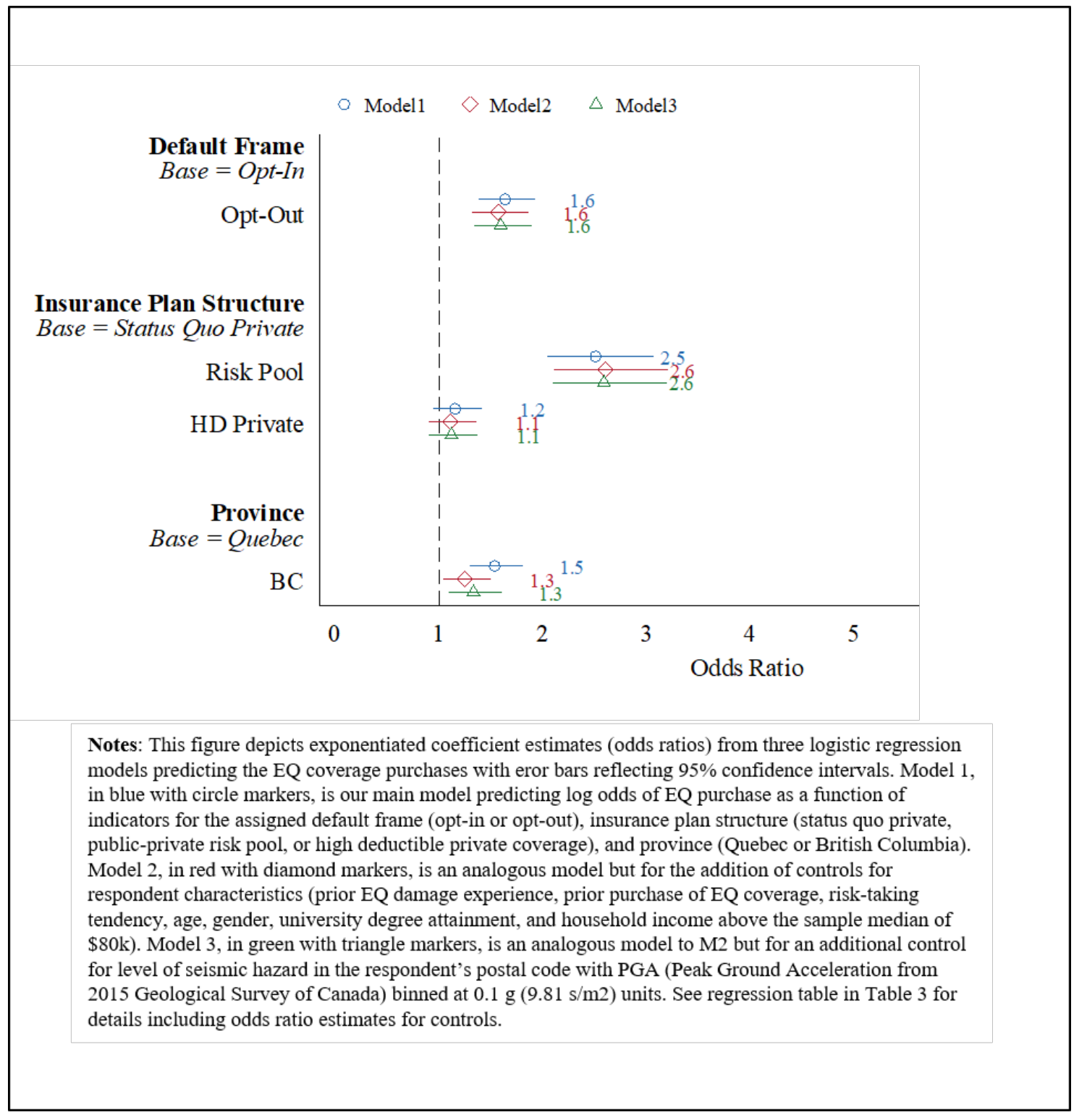


Figure 3. Share of Participants Purchasing Earthquake Coverage by Experimental Condition

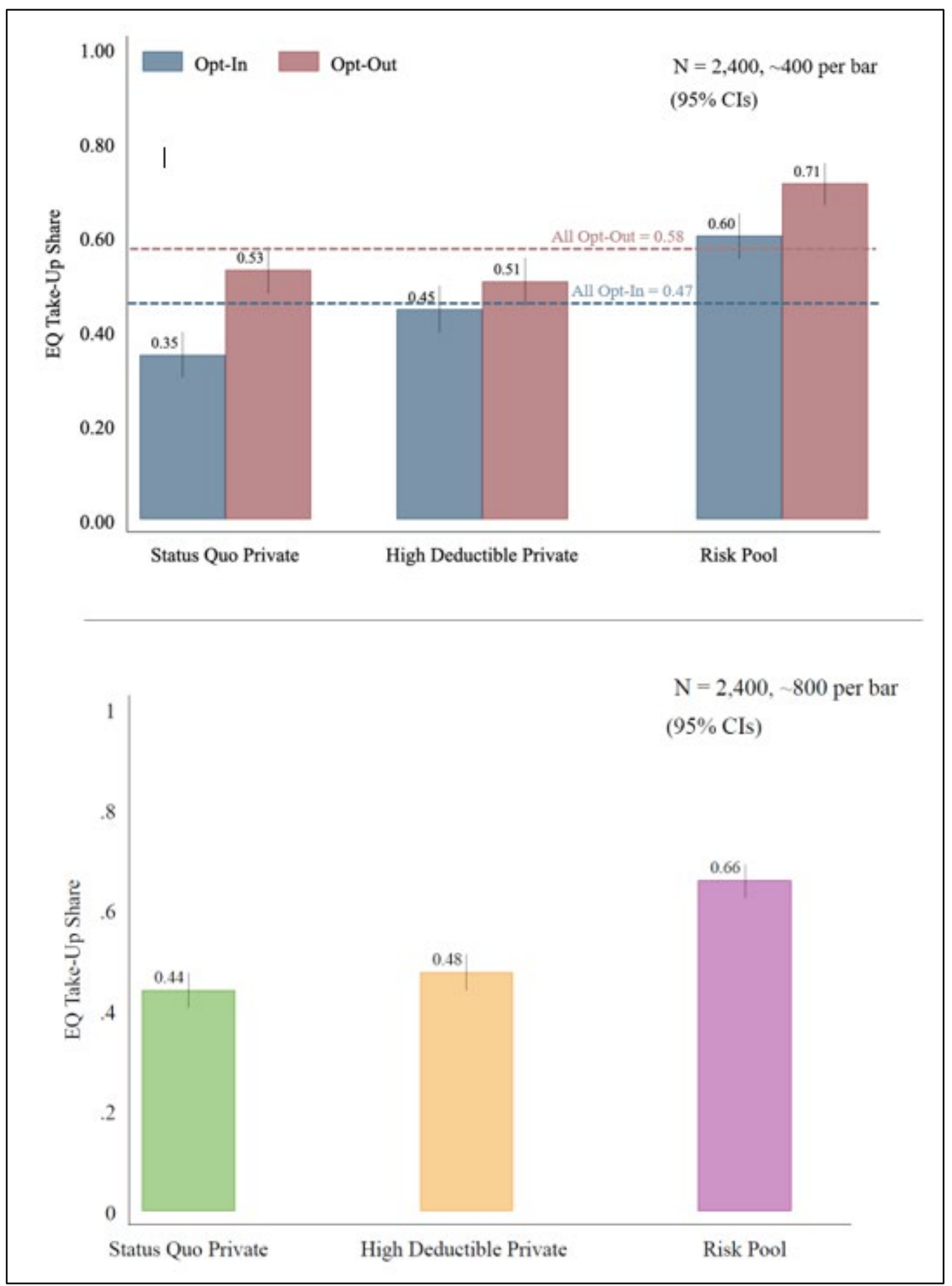


Figure 4. Earthquake Protection Take-Up Across Experimental Conditions, by Province

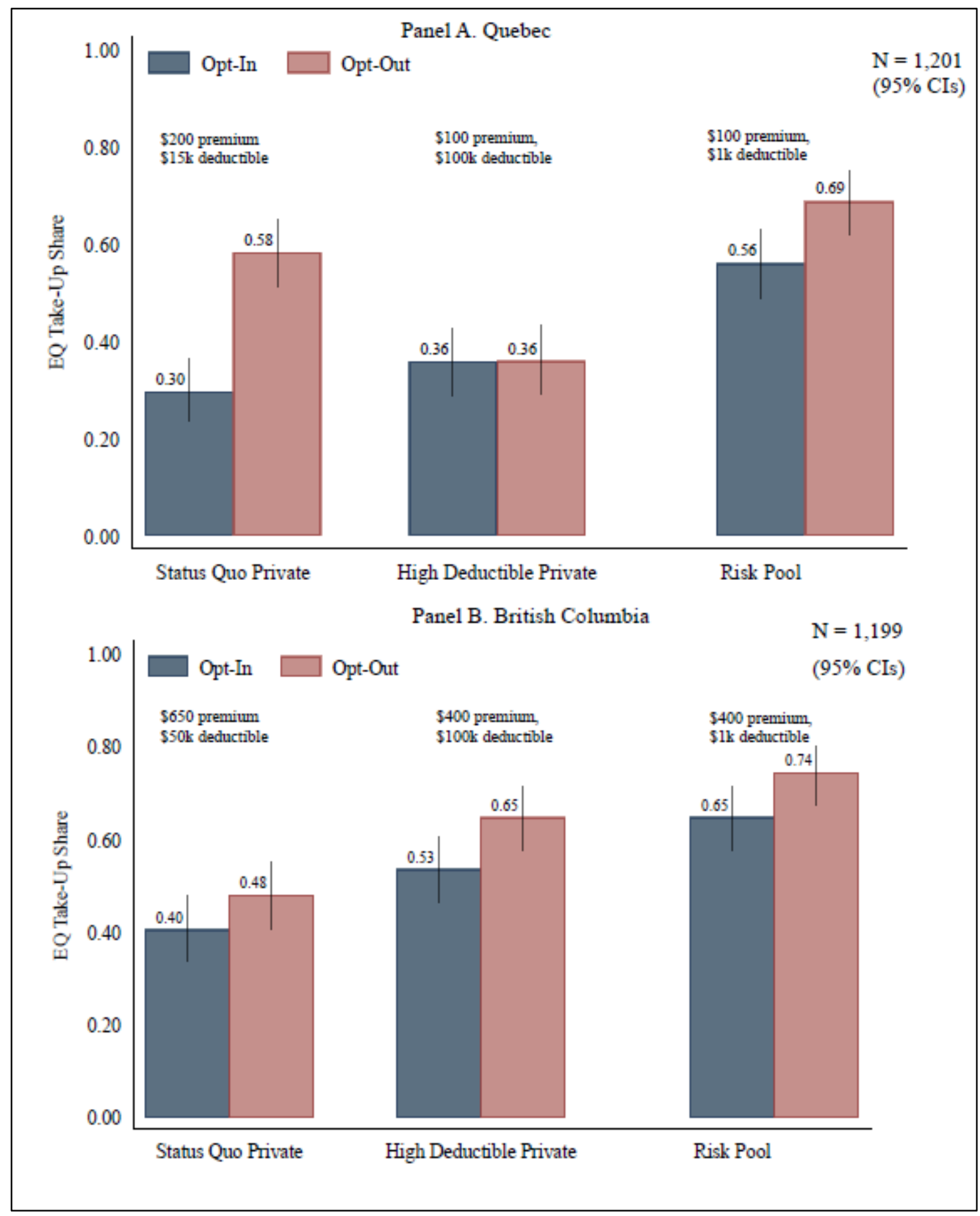


Figure 5. Order Effects on Earthquake Coverage Take-Up

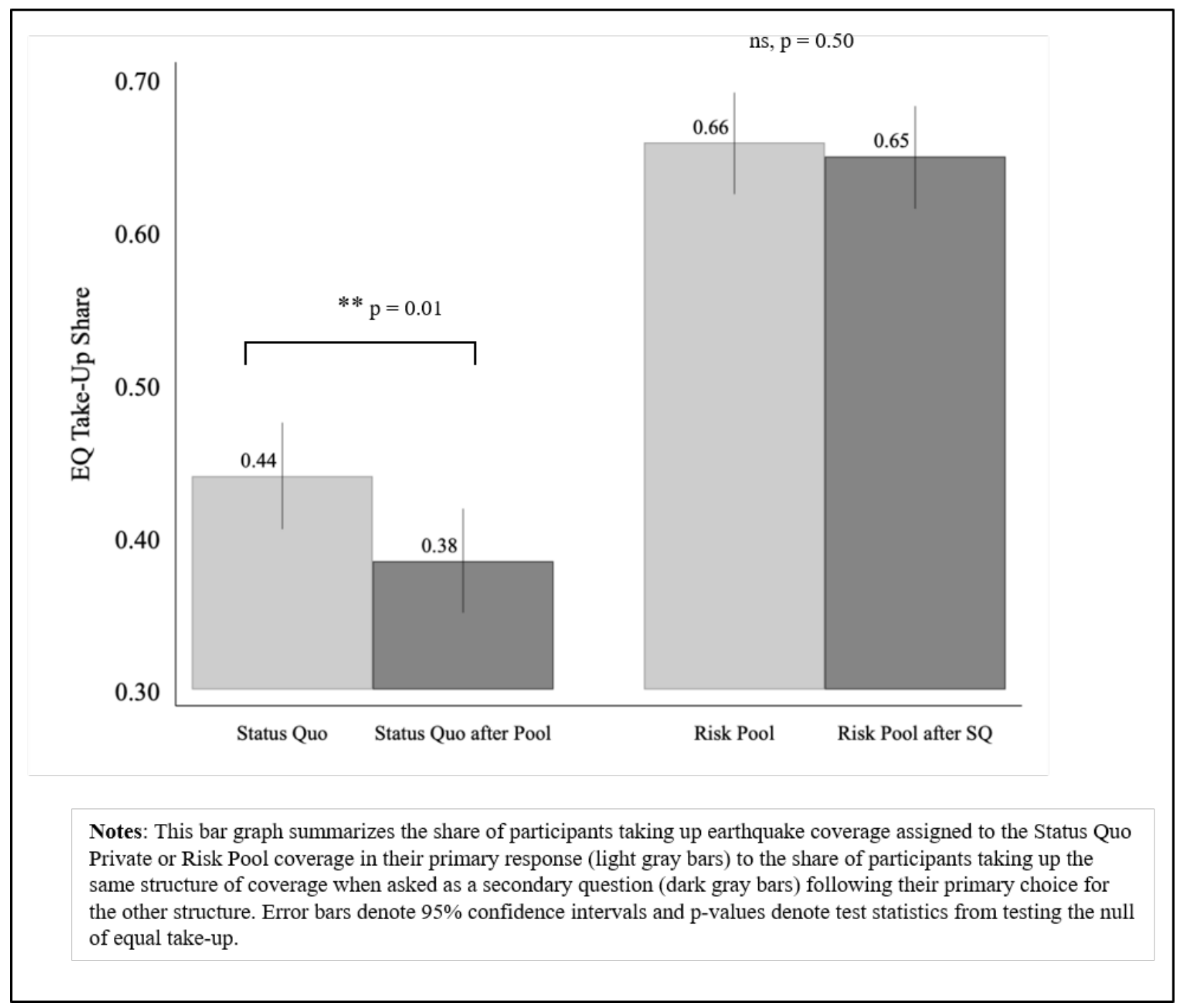




\section{References}

Bordalo, P., Gennaioli, N., \& Shleifer, A. (2012). Salience Theory of Choice Under Risk. Quarterly Journal of Economics, 127(3), 1243-1285.

Brot-Goldberg, Z. C., Layton, T., Vabson, B., \& Wang, A. Y. (2021). The Behavioral Foundations of Default Effects: Theory and Evidence from Medicare Part D (No. w28331). National Bureau of Economic Research. https://doi.org/10.3386/w28331

Cassidy, J. F., Rogers, G. C., Lamontagne, M., Halchuk, S., \& Adams, J. (2010). Canada’s earthquakes: "the good, the bad, and the ugly." Geoscience Canada, 37(1), 1+. Gale Academic OneFile.

Choi, J. J., Laibson, D., Madrian, B. C., \& Metrick, A. (2004). For better or for worse: Default effects and 401(k) savings behavior. In Perspectives on the Economics of Aging (pp. 81-126). University of Chicago Press.

Ehrlich, I., \& Becker, G. S. (1972). Market Insurance, Self-Insurance, and Self-Protection. Journal of Political Economy, 80(4), 623-648.

Goda, K., Wilhelm, K. \& Ren, J. (2020). Relationships between earthquake insurance take-up rates and seismic risk indicators for Canadian households. International Journal of Disaster Risk Reduction 50 (20) 101754

Hsee, C. K., Loewenstein, G. F., Blount, S., \& Bazerman, M. H. (1999). Preference reversals between joint and separate evaluations of options: A review and theoretical analysis. Psychological Bulletin, 125(5), 576-590. https://doi.org/10.1037/0033-2909.125.5.576

Insurance Bureau of Canada, \& AIR Worldwide. (2013). Study of Impact and the Insurance and Economic Cost of a Major Earthquake in British Columbia and Ontario/Québec. http://assets.ibc.ca/Documents/Studies/IBC-EQ-Study-Full.pdf

Johnson, E. J., \& Goldstein, D. (2003). Do Defaults Save Lives? Science, 302(5649), 1338-1339. https://doi.org/10.1126/science.1091721

Kahneman, D., \& Tversky, A. (1979). Prospect Theory: An Analysis of Decision under Risk. Econometrica, 47(2), 263-292. 
Kunreuther, H., \& Pauly, M. (2021). Do People Have a Bias for Low-Deductible Insurance? Journal of Risk and Uncertainty (in press).

Madrian, B. C., \& Shea, D. F. (2001). The Power of Suggestion: Inertia in 401(k) Participation and Savings Behavior. The Quarterly Journal of Economics, 116(4), 1149-1187. https://doi.org/10.1162/003355301753265543

O’Donoghue, T., \& Sprenger, C. (2018). Reference-Dependent Preferences. In Handbook of Behavioral Economics: Applications and Foundations 1 (Vol. 1, pp. 1-77). Elsevier. https://doi.org/10.1016/bs.hesbe.2018.07.003

Robinson, P. J., Botzen, W. J. W., Kunreuther, H., \& Chaudhry, S. J. (2020). Default Options and Insurance Demand. Journal of Economic Behavior \& Organization. https://doi.org/10.3386/w27381

Sydnor, J. (2010). (Over)insuring Modest Risks. American Economic Journal: Applied Economics, 2(4), 177-199. https://doi.org/10.1257/app.2.4.177 


\section{Appendix A.}

Figure A1 reports prior coverage among respondents in the Quebec (QC) and British Columbia (BC) surveys and CatIQ average current coverage across respondent 3-digit postal codes. It is followed by the Web-Based Experiment Instrument for Quebec homeowners

\section{Appendix Figure A1. Shares of Reported Prior EQ Insurance Coverage and Current Observed Coverage across FSAs Ordered by Seismic Hazard, by province}

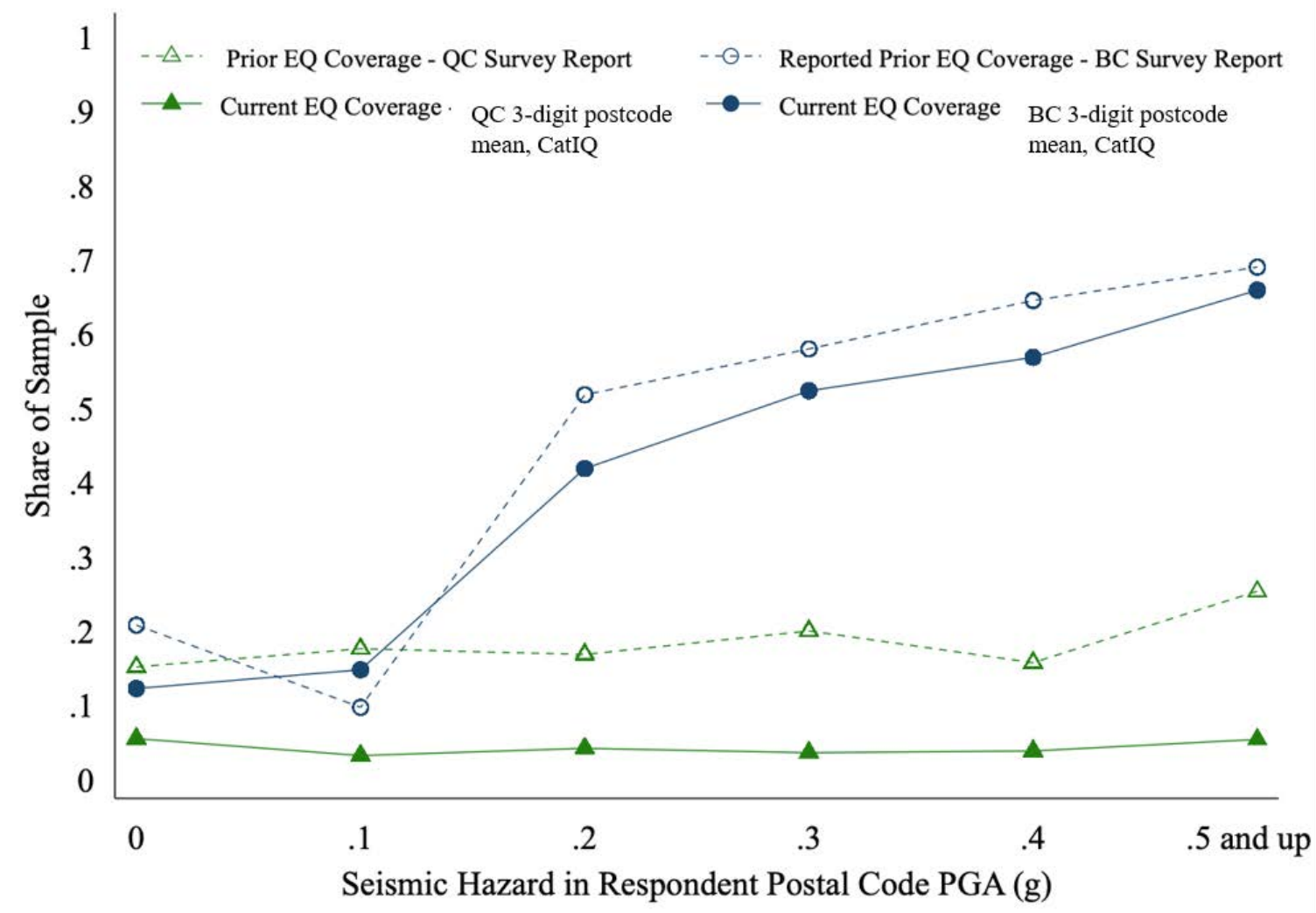

Notes: This graph compares the share of respondents reporting prior EQ insurance coverage (hollow markers, dashed lines) to the current share of EQ insured homes from CatIQ data (filled markers, solid lines) at the respondent 3-digit postal code level binned by increasing seismic hazard as reflected in PGA (peak ground acceleration) from Geological Survey of Canada. PGA is expressed in units $\mathrm{g}(9.81 \mathrm{~m} / \mathrm{s} 2)$ and binned in increments of 0.1 up to a category postal codes with PGA 0.5 or higher (top category defined such that all levels contain over 100 respondents). 


\section{Web-Based Experiment Instrument for Quebec homeowners}

[Italicized text in brackets denote information about questions that were only displayed to some respondents based on experimental assignment or prior responses.]

Page Break

Would you prefer to view this survey in English or French?

Préférez-vous répondre à cette enquête en anglais ou en français?

English. O français

\section{Page Break}

Thank you for your interest in participating in this research. This survey was designed by researchers at the University of Pennsylvania and the Institute for Catastrophic Loss Reduction (Canada) to better understand how individuals make decisions relating to earthquake insurance. It should take you 5 to 10minutes to complete.

Please review the following information:

\section{Your Participation is Voluntary}

Your participation in this survey is voluntary. You may discontinue participation at any time during the survey by exiting the survey.

\section{Confidentiality}

We will make every effort to keep all the information you provide us during the study strictly confidential, except as required by law. Your name and other identifying information will not be connected with the responses you provide, so no one will be able to identify you in any publications that result from this research.

\section{Payment and Benefits}

Beyond the payment you receive for survey completion through LEO there will be no direct benefits of the study.

\section{Questions}

If you have questions regarding this research or your participation in it, please contact the researchers at lynnp@wharton.upenn.edu. If you have questions about your rights as a volunteer in this research study, you can contact the University of Pennsylvania Office of Regulatory Affairs at 215-898-2614.

Please confirm the statements below and click "Next" to proceed.

I am age 18 or older.

I have read and understand the information above.

I want to participate in this research and continue with the task.

I want to participate in this research and continue with the task. 
Before proceeding to the study instructions, we have a few quick questions about you.

1. What is your birth year?

2. What is your current living situation?

I am a homeowner $\bigcirc$ I am a renter $\mathrm{O}$ other

3. In which country do you currently reside?

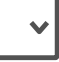

Page Break

4. In which province do you currently reside?

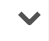

Page Break

Please consider the following situation and rate the items below: This is an attention check. Simply select the number 4 for each of the 5 items below.

\begin{tabular}{|c|c|c|c|c|c|}
\hline & $\begin{array}{l}\text { Not at all } \\
\text { important }\end{array}$ & $\begin{array}{l}\text { Slightly } \\
\text { important }\end{array}$ & $\begin{array}{l}\text { Moderately } \\
\text { important }\end{array}$ & Very important & $\begin{array}{l}\text { Extremely } \\
\text { important }\end{array}$ \\
\hline & 1 & 2 & 3 & 4 & 5 \\
\hline $\begin{array}{l}\text { Work } \\
\text { colleagues }\end{array}$ & & & & & \\
\hline Parents & & 0 & 0 & & \\
\hline Siblings & & & & & \\
\hline Family friends & & 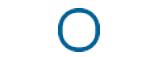 & ) & 0 & 0 \\
\hline Acquaintances & & & & & \\
\hline
\end{tabular}

\section{Page Break}

In this survey, we will ask you to consider information and answer questions related to earthquake risk and insurance.

On the next page, you will read about a hypothetical scenario and make decisions related to insurance. Please read the information carefully and make your choices as you would if you faced the situation in real life.

Page Break

Hypothetical Scenario: Assume that you own a house in Quebec that would cost $\$ 400,000$ to rebuild if significantly damaged by an earthquake. There is a 1 in 10 chance of an earthquake that will cause damage in Quebec during the next 50 years. If an earthquake were to damage your home, the average cost to repair the damage is $\$ 115,000$ with a 1 in 13chance the house would have to be completely rebuilt at a cost of $\$ 400,000$. 


\section{Page Break}

Reminder of Hypothetical Scenario: Assume that you own a house in Quebec that would cost $\$ 400,000$ to rebuild if significantly damaged by an earthquake. There is a 1 in 10 chanceof an earthquake that will cause damage in Quebec during the next 50 years. If an earthquake were to damage your home, the average cost to repair the damage is $\$ 115,000$ with a 1 in 13 chance the house would have to be completely rebuilt at a cost of $\$ 400,000$.

[If Assigned Insurance Plan Structure = Status Quo Private \& default frame = Opt-In]

You currently have home insurance that covers theft losses and fire damage at a cost of $\$ 1,000$ a year. Suppose the only available way to cover earthquake damage is private home insurance. Should you decide to purchase earthquake coverage on your home insurance policy, you would be responsible for the first $\$ 15,000$ in damage and insurance would coverdamage exceeding $\$ 15,000$.

\section{Would you pay an additional $\$ 200$ to purchase earthquake insurance?}

$\bigcirc$ Yes $O$ No

[If Assigned Insurance Plan Structure = Status Quo Private \& default frame = Opt-Out]

Suppose you have a home insurance policy covering theft, fire damage and earthquake damage to your home at a total cost of $\$ 1,200$ a year. For earthquake damage you would beresponsible for the first $\$ 15,000$ in damage and your insurance policy would cover losses that exceed $\$ 15,000$.

Would you choose to remove earthquake coverage and reduce the annual cost of homeinsurance by $\mathbf{\$ 2 0 0 ?}$

$\bigcirc$ Yes $\bigcirc$ No

[If Assigned Insurance Plan Structure = Risk Pool \& default frame $=$ Opt-In]

You currently have home insurance that covers theft losses and fire damage at a cost of $\$ 1,000$ a year. Suppose the government and private insurers develop an earthquake risk poolthat covers earthquake damage to your house that exceeds $\$ 1,000$. You would be responsible for the first $\$ 1,000$ in damage. The risk pool would cover losses that exceed $\$ 1,000$.

Would you pay an additional $\$ 100$ to participate in the earthquake risk pool?

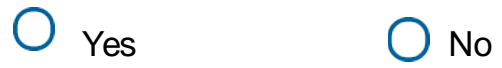

[If Assigned Insurance Plan Structure $=$ Risk Pool \& default frame $=$ Opt-Out]

Suppose you have a home insurance policy covering theft and fire damages. The government and private insurers develop an earthquake residential risk pool that covers earthquake damage to your house. For earthquake damage, you would be responsible for the first $\$ 1,000$ in damage. The risk pool would cover losses that exceed $\$ 1,000$. This coverage has been appended to your home insurance policy, but you have the option of removing it. The total cost of protection against fire, theft and earthquake damage is $\$ 1,100$.

Would you remove earthquake coverage from your home insurance by not joining theearthquake risk pool and reduce your annual cost by $\$ 100$ ?

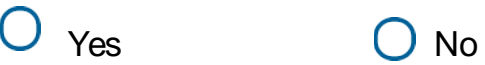

[If Assigned Insurance Plan Structure structure = High Deductible Private \& Default frame = Opt-In] You currently have home insurance that covers theft losses and fire damage at a cost of $\$ 1,000$ a year.

Private insurers offer earthquake insurance that will cover any earthquake damage over $\$ 100,000$ to your 
house.

Would you pay an additional $\$ 100$ to purchase earthquake insurance?

$\bigcirc$ Yes $\bigcirc$ No

[Assigned Insurance Plan Structure = High Deductible Private \& Default frame $=$ Opt-Out]

You currently have home insurance covering theft, fire damage and earthquake damage toyour home above $\$ 100,000$ at a total cost of $\$ 1,100$ a year.

Would you choose to remove earthquake coverage and reduce the annual cost of yourinsurance by $\$ 100$ ?

Yes $\bigcirc$ No

Page Break

This next group of questions relate to the house in the scenario you just considered.

Please answer these questions with reference to the information you had in mind while making choices in the scenario.

In the event that the house in the scenario is damaged by an earthquake, what was your estimate of the total damage amount?

Damage Estimate: \$

I did not think of a damage estimate

\section{Page Break}

How worried were you about an earthquake damaging the house in the next 50 years?

Not at all A little worried Somewhat worried Moderately worried Very worried Extremely worried worried

Page Break

How likely did you think it was that the house in the scenario would be damaged by anearthquake in the next $\mathbf{5 0}$ years?

Please select the category that contains your estimate of this likelihood

Greater than 1 in 10 chance

Between 1 in 100 and 1 in 1,000 chance.

Between 1 in 10,000 and 1 in 100,000 chance chance
Between 1 in 10 and 1 in 100 chance

Between 1 in 1,000 and 1 in 10,000 chance

Between 1 in 100,000 and 1 in 1,000,000

Less than 1 in 1,000,000 chance 


\section{Page Break}

[Displayed if prior question response="Between 1 in 100,000 and 1 in 1,000,000 chance"]

For that same estimate of the house's likelihood of being damaged by an earthquake inthe next 50 years:

Please indicate your best estimate of damage likelihood on the slider below within the rangeyou selected from 1 in 1,000,000 chance of occurring up to 1 in 100,000 chance.

\section{Low}

1 in

$1,000,000$

\section{Page Break}

This next group of questions are all about your real life

Have you ever experienced earthquake damage to a home in which you lived?

$\bigcirc$ Yes $\bigcirc$ No

\section{Page Break}

[Displayed if prior question response $=$ Yes]

What is the most recent year that you experienced earthquake damage to your home?

\section{Page Break}

\section{What types of insurance have you had before?}

Please select ALL that apply.

$\square$ Flood insurance

$\square$ Homeowner's insurance

$\square$ Auto insurance

$\square$ Health insurance

$\square$ Earthquake insurance

$\square$ None of the above

Page Break 
In general, are you a person who is more willing or unwilling to take risks?

$\begin{array}{ccccccccc}\begin{array}{c}\text { Extremely } \\ \text { unwilling to } \\ \text { take risks }\end{array} & & & & & & & \begin{array}{c}\text { Extremely } \\ \text { willing to take } \\ \text { risks }\end{array} \\ 1 & 2 & 3 & 4 & 5 & 6 & 7 & 8 & 9 \\ 0 & 0 & 0 & 0 & 0 & 0 & 0 & 0 & 0 \\ 0\end{array}$

\section{Page Break}

What is your gender?

male Ofemale $\bigcirc$ other

What is the highest level of school you have completed?

Less than high school

High school

Some university

University degree (e.g., Bachelor or Associate degree)

Advanced degree (e.g. Masters, Doctoral, or Professional degrees)

What was your total household income last year?

Please think of income from all sources in 2020 before taxes.

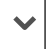

What is your postal code?

Page Break

You've completed the study, thank you for participating!

Please click "Submit" to record your responses and be redirected to LEO.

Let us know below if you experienced any problems with the study or have questionsor comments [Optional]. 